\title{
Totally robotic sutured coronary artery bypass grafting: How we do it
}

Gianluca Torregrossa, MD, Andrea Amabile, MD, and Husam H. Balkhy, MD, Chicago, Ill

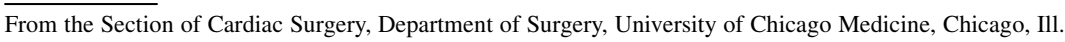
Disclosures: Dr Balkhy has served as a proctor for Intuitive Surgical. All other authors reported no conflicts of interest.

The Journal policy requires editors and reviewers to disclose conflicts of interest and to decline handling or reviewing manuscripts for which they may have a conflict of interest. The editors and reviewers of this article have no conflicts of interest.

Patient informed consent was obtained to publish the video and photographs included in this manuscript.

Received for publication May 19, 2020; revisions received May 19, 2020; accepted for publication May 20, 2020; available ahead of print May 28, 2020.

Address for reprints: Husam H. Balkhy, MD, University of Chicago Medicine, 5841 S Maryland Ave, Chicago, IL 60637 (E-mail: hbalkhy@surgery.bsd.uchicago.edu).

JTCVS Techniques 2020;3:170-2

2666-2507

Published by Elsevier Inc. on behalf of The American Association for Thoracic Surgery. This is an open access article under the CC BY-NC-ND license (http://creativecommons.org/licenses/by-nc-nd/4.0/).

https://doi.org/10.1016/j.xjtc.2020.05.018

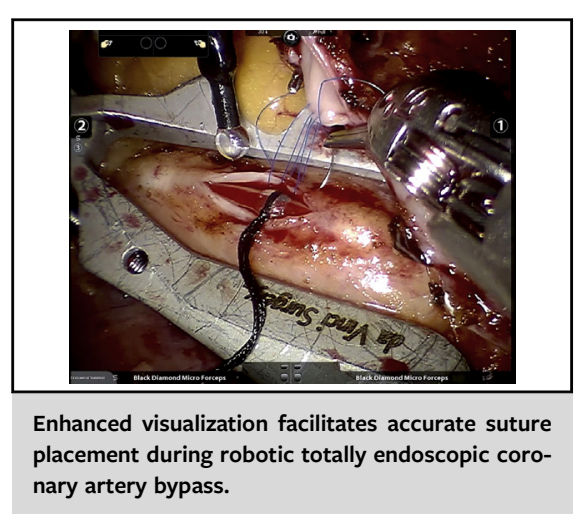

CENTRAL MESSAGE

Totally endoscopic coronary artery bypass provides the benefit of multiarterial grafting while minimizing the risk of wound infection and stroke. We present our technique to reproducibly perform a totally robotic sutured coronary anastomosis.

See Commentaries on pages 173 and 174.
While the production of distal anastomotic connectors has been suspended, a hand-sewn technique has become essential to continue to perform off-pump closed chest multiarterial bypass surgery. ${ }^{1,2}$ Totally endoscopic coronary artery bypass (TECAB) provides the benefit of multiarterial grafting while minimizing the risk of wound infection and stroke. Here we describe our technique for reproducibly performing a totally robotic sutured coronary anastomosis.

\section{TECHNIQUE}

Patient setup, anesthesia management, port insertion, and internal thoracic artery (ITA) harvesting have been described previously. ${ }^{3-5}$ In brief, the camera port is placed in the left fourth intercostal space (ICS) and instrument ports are placed in the second and sixth ICSs, all in the anterior-axillary line. The da Vinci Si System (Intuitive Surgical, Sunnyvale, Calif) is docked from the right side, with the robotic cart positioned at 60-degree angle from the table. Continuous $\mathrm{CO}_{2}$ insufflation is required to compress the lung and provide space to conduct the operation. A subcostal fourth arm for the Endo-Wrist stabilizer is inserted, and a $12-\mathrm{mm}$ sealed working port is advanced in the second ICS at the midclavicular line.

The coronary target(s) are exposed with the aid of the stabilizer. The overlying epicardium is dissected using low electrocautery and a silastic snare (SaddleLoop; Quest Medical, Allen, Tex) is placed proximally. After heparinization, the ITA conduits are divided distally. A 30-degree down scope is used for the left anterior descending artery anastomosis, and a 30-degree up scope (or 0degree scope) is chosen for the left circumflex branches. Ischemic preconditioning for 5 to 8 minutes with coronary snaring is recommended, under careful observation with electrocardiographic monitoring, hemodynamic response, and transesophageal echocardiography. During this period, sutures and shunts can be delivered into the chest cavity through the working port. At this time, the distal end of the ITA is clipped onto a silk tie that had been previously secured to the stabilizer to offer a consistent landing zone of the ITA in proximity to the coronary target. (Figure 1, $A$ and $B$ ). A bulldog clamp is applied onto the ITA, and at this time, its distal end is usually transected and trimmed to the appropriate length using Potts scissors.

After a short reperfusion period, the snare is tightened, and a coronary arteriotomy is made using an endo-knife 


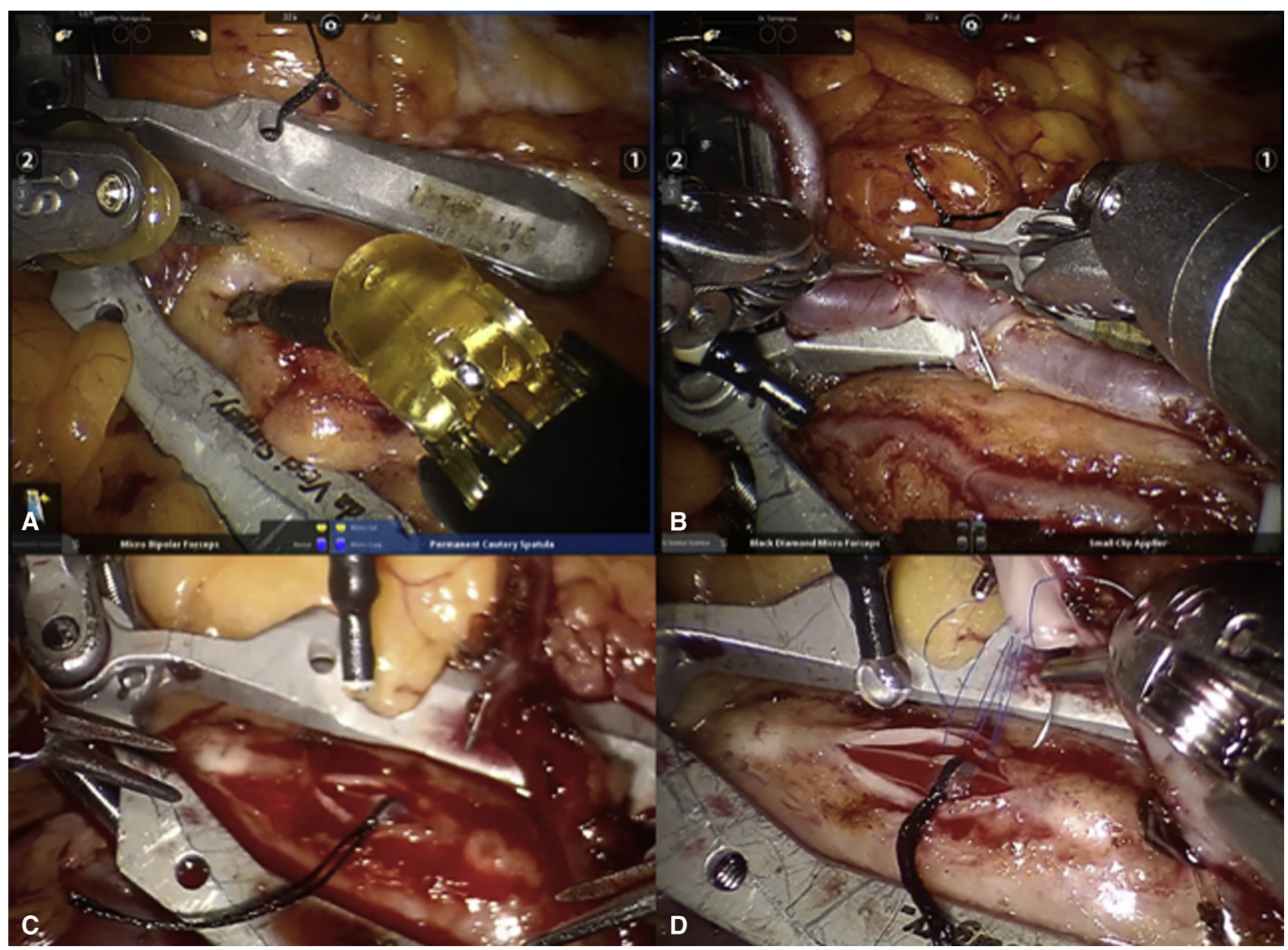

FIGURE 1. Totally robotic sutured coronary anastomosis of left internal thoracic artery to left anterior descending coronary artery. A, Identification of distal coronary target with the aid of robotic stabilizer. B, Securing the conduit on the robotic stabilizer to offer a consistent landing zone of the internal thoracic artery in proximity with the coronary target. C, Opening of the coronary target and introduction of the coronary shunt. D, Suturing using Pronova 7/0 (Johnson \& Johnson Medical, New Brunswick, NJ).

and elongated with Potts scissors. Then both robotic arms are loaded with Black Diamond forceps, and the coronary shunt is placed, with subsequent release of the snare (Figure 1, C).

The anastomosis is performed in a continuous running fashion, using a short double-armed 7-0 PRONOVA suture (Johnson \& Johnson Medical, New Brunswick, NJ).

One needle is loaded backhand and passed inside-out in the middle of the coronary arteriotomy on the side farthest from the surgeon (12 o'clock position) (Figure 1, D). The stitch is then pulled to equally distribute the length between the 2 ends, and the needle is anchored away from the surgeon's view. The second needle is retrieved and loaded forehand and passed inside-out halfway on the corresponding side of the ITA. This needle is progressed in a continuous fashion toward the heel of the anastomosis.
After a few stitches, the graft is parachuted onto the coronary target. Frequent tightening of the suture is mandatory (Figure 2, B). The same needle is progressed around the heel up to 5 o'clock from the surgeon's view. During the heel bites, a second shunt can be placed inside the ITA to protect its backwall. The suture is retightened, and the first needle is retrieved and loaded backhand.

This needle is passed outside-in in the graft and then inside-out in the coronary target, proceeding toward the toe of the anastomosis. After rounding the toe, the needle is loaded forehand, and the left robotic instrument is used to create countertraction by pulling the suture while advancing the stitch. Before completing the toe, care is taken to tighten the suture. The same needle is advanced to the heel, and the anastomosis completed at the 5 o'clock position on the surgeon's view (Figure 2, $A-C$ ). 


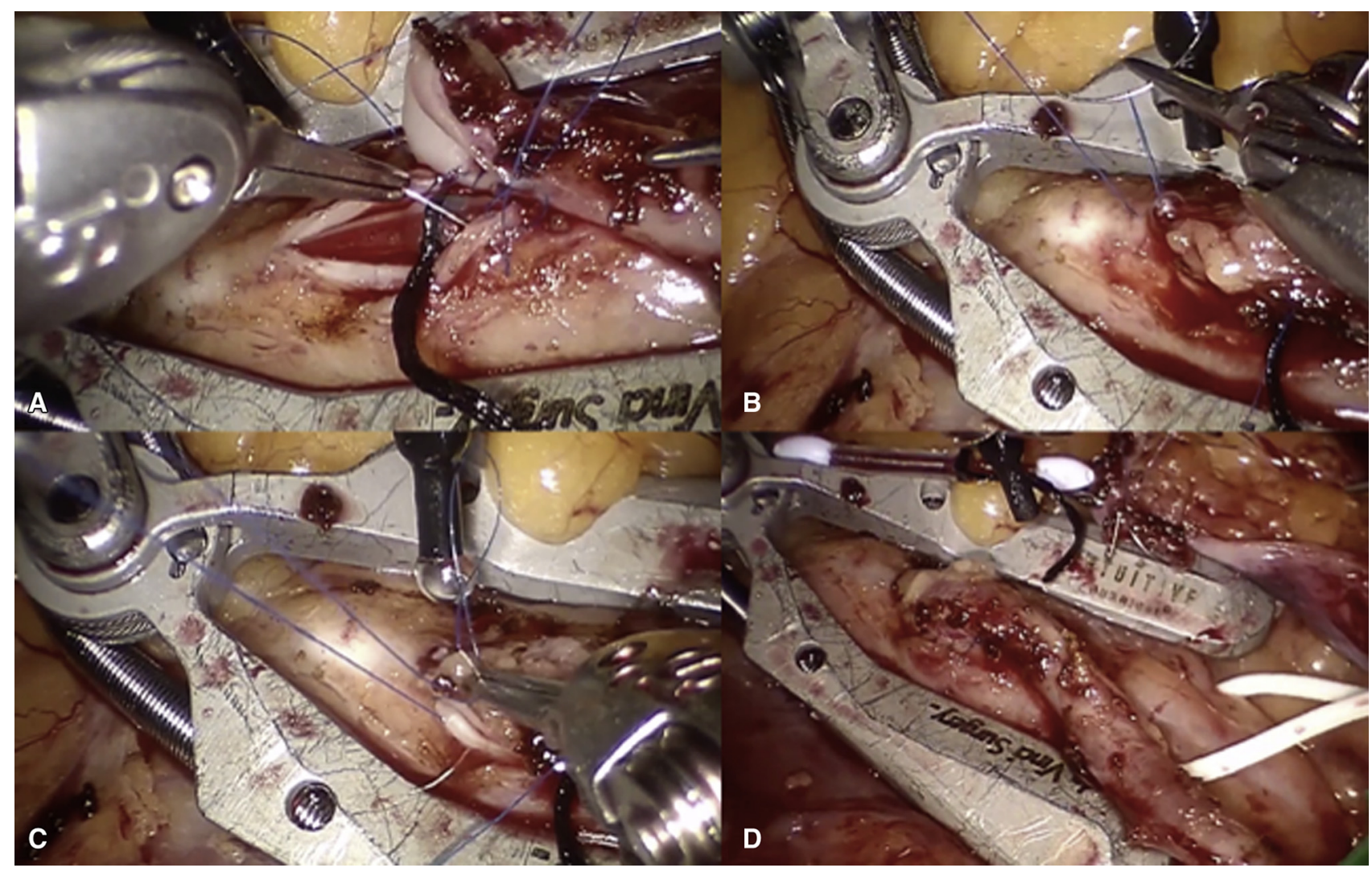

FIGURE 2. Suturing a left internal thoracic artery to left anterior descending coronary artery. A, First step is to proceed to the heel then (B) reload the first suture to proceed to the toe of the anastomosis. C, Progression with needle 1 toward the heel. D, Completed anastomosis.

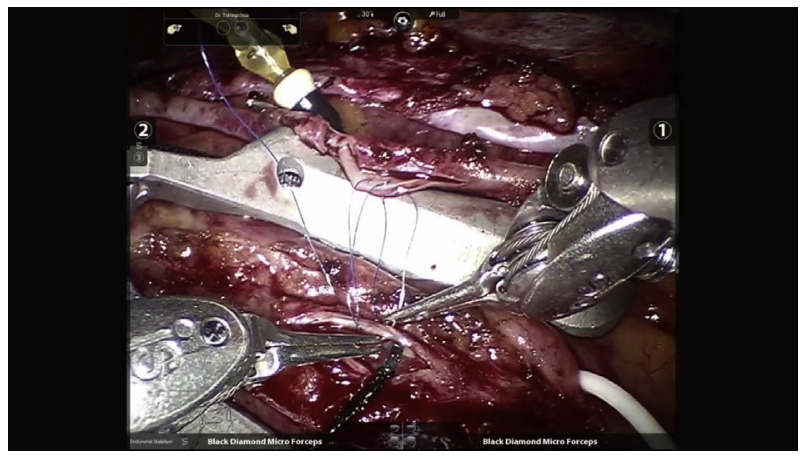

VIDEO 1. Robotic-sutured left internal thoracic artery-to-left anterior descending coronary artery anastomosis. Video available at: https://www. jtcvs.org/article/S2666-2507(20)30239-X/fulltext.

After deairing, the shunt is removed, and knots are tied under careful visualization. Finally, the bulldog clamp and the proximal snare are released, and each anastomosis is assessed with transit time flowmetry (Video 1).

\section{References}

1. Kitahara H, Nisivaco S, Balkhy HH. Graft patency after robotically assisted coronary artery bypass surgery. Innovations (Phila). 2019;14: 117-23.

2. Balkhy HH, Nisivaco S, Kitahara H, McCrorey M, Patel B. Robotic beating heart totally endoscopic coronary artery bypass in higher-risk patients: can it be done safely? Innovations (Phila). 2018;13:108-13.

3. Hashimoto M, Wehman B, Balkhy HH. Robotic totally endoscopic coronary artery bypass: tips and tricks for using an anastomotic device. J Thorac Cardiovasc Surg. 2020;159e:57-60.

4. Balkhy HH, Gummert JF. Beating heart: totally endoscopic coronary artery bypass surgery; robotic endoscopic multi-vessel anastomotic connectors. In: Chitwood W Jr., ed. Atlas of Robotic Cardiac Surgery. London: Springer; 2014: 97-105.

5. Balkhy HH, Wann LS, Krienbring D, Arnsdorf SE. Integrating coronary anastomotic connedtors and troboticws towards a totally endoscopic beating heart approach: review of 120 cases. Ann Thorac Surg. 2011;92: $821-7$. 